\title{
Correction to: A green biorefinery platform for cost-effective nanocellulose production: investigation of hydrodynamic properties and biodegradability of thin films
}

\author{
Reshmy R. ${ }^{1}$ Eapen Philip ${ }^{1}$. Sherely A. Paul ${ }^{1}$ - Aravind Madhavan ${ }^{2} \cdot$ Raveendran Sindhu $^{3} \cdot$ Parameswaran Binod $^{3}$. \\ Ashok Pandey ${ }^{4}$
}

Published online: 10 October 2020

(C) Springer-Verlag GmbH Germany, part of Springer Nature 2020

\section{Correction to: Biomass Conversion and Biorefinery}

https://doi.org/10.1007/s13399-020-00961-1

The original version of this article unfortunately contained a mistake. The authors' given and family names were switched. The corrected author names are shown above.

The original article has been corrected.

Publisher's Note Springer Nature remains neutral with regard to jurisdictional claims in published maps and institutional affiliations.

The online version of the original article can be found at https://doi.org/ 10.1007/s13399-020-00961-1

$\triangle$ Reshmy R.

reshmypkumar@gmail.com

1 Post Graduate and Research Department of Chemistry, Bishop Moore College, Mavelikara, Kerala 690 110, India

2 Rajiv Gandhi Centre for Biotechnology, Jagathy, Thiruvananthapuram, Kerala 695 014, India

3 Microbial Processes and Technology Division, CSIR-National Institute for Interdisciplinary Science and Technology (CSIR-NIIST), Thiruvananthapuram, Kerala 695 019, India

4 Centre for Innovation and Translational Research, CSIR - Indian Institute for Toxicology Research (CSIR-IITR), 31 MG Marg, Lucknow 226 001, India 